\title{
Discutindo Conceitos De Educação Ambiental Com Professores Em Uma Escola Pública De São Paulo
}

\author{
Discussing Concepts of Environmental Education With Teachers at a \\ Public School of São Paulo
}

\section{Terezinha Marisa Ribeiro de Oliveira ${ }^{1}$; Carmem Lúcia Costa Amaral ${ }^{2}$}

1.Doutoranda em Ensino de Ciências e Matemática, Universidade Cruzeiro do Sul, São Paulo, São Paulo, Brasil terezinha.marisa@gmail.com/ https://orcid.org/0000-0002-9064-8518

2.Doutora em Química Orgânica, Universidade Cruzeiro do Sul, São Paulo, São Paulo, Brasil carmem.amaral@cruzeirodosul.edu.br/ https://orcid.org/0000-0002-6495-153X

\section{Recebido em 26/10/2018. Publicado em Agosto/2019}

\section{Palavras-chave:}

V de Gowin. Educação

Ambiental. Formação de professores.

\author{
Keywords: \\ Gowin's V. \\ Environmental \\ education. Teacher \\ training
}

RESUMO: A preocupação com o meio ambiente em nossa sociedade é crescente, seja nos veículos de comunicação em massa ou mesmo em revistas especializadas e a escola não pode ficar fora dessa preocupação. Para isso é importante que o professor tenha conhecimento de conceitos que envolvem a Educação Ambiental (EA). Desta forma, este artigo descreve o resultado de uma experiência realizada com professores do Ensino Fundamental e Médio que teve como objetivos discutir alguns conceitos de Educação Ambiental. O objetivo dessa discussão foi que os professores de todas as áreas percebessem a educação ambiental como tema transversal e propusessem ações que poderiam ser desenvolvidas na escola. Os conceitos de educação ambiental escolhidos para essa discussão foram os de Loureiro (2004), Sato et al. (2005), Sorrentino et al. (2005), Quintas (2008), Layrargues (2002), Mousinho (2003) e Trein (2008) que estão disponíveis no portal do Ministério do Meio Ambiente. Essa experiência foi desenvolvida em uma escola pública localizada no estado de São Paulo e envolveu 35 professores de todas as áreas do conhecimento. Os resultados evidenciaram que os professores não conheciam esses conceitos e que somente os de Biologia e Ciências desenvolviam projetos de EA de forma isolada. A partir do estudo e discussão desses conceitos, esses professores compreenderam que a EA deve ser desenvolvida na escola de forma transversal e interdisciplinar e que deve ser incorporada ao Projeto Político Pedagógico da Escola.

ABSTRACT: The concern for the environment in our society is growing, either in mass media or even in specialized magazines, and the school cannot stay out of that concern. For this it is important that the teacher knows concepts that involve Environmental Education (EE). In this way, this article describes the result of an experience with elementary and high school teachers that had the objective of discussing some concepts of EE. The objective of this discussion was that teachers from all areas could realize the environmental education as a cross-cutting theme and propose actions that could be developed at school. The concepts of EE chosen for this discussion were those of Loureiro (2004), Sato et al. (2005), Sorrentino et al. (2005), Quintas (2008), Layrargues (2002), Mousinho (2003) and Trein (2008) available on the Ministry of the Environment website. We have developed this experience at a public school located in the state of São Paulo and it involved 35 teachers from all areas of knowledge. The results showed that the teachers did not know these concepts and that only Biology and Science teachers developed EE projects in isolation. From the study and discussion of these concepts, these teachers understood that EE should be developed at school in a transversal and interdisciplinary way and that it should be incorporated into the School's Political Educational Project. 


\section{INTRODUÇÃO}

A Educação Ambiental (EA) de acordo com a Lei no 9.795 “é um componente essencial e permanente da educação Nacional, devendo estar presente em todos os níveis e modalidades do processo educativo formal e não formal" (BRASIL, 1999). Porém, o que se tem observado atualmente é que esta apresenta-se de forma fragmentada na escola e essa fragmentação se deve ao despreparo dos professores para trabalhar a temática ambiental.

Esse despreparo ocorre, muitas vezes, pela deficiência da abordagem da EA em cursos de formação inicial de professores. Várias pesquisas apontam essa deficiência e a dificuldade dos professores em trabalhar as questões ambientais em sala de aula. Entre essas pesquisas está a desenvolvida por Oliveira (2015). De acordo com seus resultados, as dificuldades apontadas pelos professores são a falta de recursos humanos qualificados, dificuldade da comunidade escolar em entender as questões ambientais e precariedade dos recursos materiais. Metade dos professores pesquisados disseram que à EA não foi contemplada nos seus cursos de formação inicial.

Um resultado similar foi encontrado por Coelho-Miyazawa, Curi e Frenedozo (2017) que ao analisaram a inserção da EA na formação inicial de professores em dissertações e teses desenvolvidas nos programas de pós-graduação brasileiros, no período de 2010 a 2016, identificaram ausência de atividades envolvendo a EA nesses cursos.

Uma forma de suprir essa deficiência é a participação dos professores em cursos de formação continuada. Entretanto, o que se tem observado é que, em geral, esses são restritos a professores de Ciências e de Biologia. Assim, compreendendo que a EA é um componente fundamental em todas as áreas do conhecimento, nesse artigo descreve-se o resultado de uma experiência realizada com professores do Ensino Fundamental e Médio de todas as áreas do conhecimento que teve como objetivo discutir alguns conceitos de EA.

O objetivo dessa discussão foi que os professores a partir desses conceitos percebessem a EA como tema transversal e propusessem ações que poderiam ser desenvolvidas na escola, uma vez que, nessa escola, as questões ambientais são discutidas somente nas disciplinas de Ciências e Biologia, ficando os professores de outras disciplinas a desenvolverem projetos isolados, seja com o tema que por vezes argumentam não pertencer às suas disciplinas, ou por barreiras de convívio.

Nessa escola, os projetos de EA quando desenvolvidos por esses professores servem somente para cumprir um roteiro estabelecido por algum órgão governamental que tem uma obrigação com uma determinada legislação ou datas comemorativas. Como consequência esses projetos são curtos e pouco fazem sentido tanto para esses professores quanto para seus alunos. 
Ensino, Saúde e Ambiente - V12 (2), pp. 140-155, Ago. 2019

Com essa experiência, esperava-se que o professor(a) compreendesse a EA não somente como um tema transversal, mas também como uma temática que deve ser contemplada no Projeto Político Pedagógico (PPP) da Escola.

\section{EDUCAÇÃO AMBIENTAL}

O interesse mundial pelas questões ambientais iniciou a partir da década de 1960 e se fortaleceu na Conferência de Estocolmo, em 1972, onde se atribuiu a inserção da temática da EA na agenda internacional. Essa Conferência declarou como objetivo primordial a defesa e a melhoria do meio ambiente para as gerações atuais e futuras.

No Brasil, segundo Luca, Lagazzi e Sorrentino (2011) a implantação da EA se deu como consequência da pressão internacional da Organização das Nações Unidas para que o tema estivesse nas agendas do governo como reflexo da Conferência de Estocolmo. Assim, em 1973, foi criada a Secretaria Especial de Meio Ambiente e este foi o primeiro órgão federal que teve como um dos seus objetivos executar ações de proteção ambiental.

Em 1975, no Congresso de Belgrado (na então Iugoslávia) foi lançado o Programa Internacional de Educação Ambiental, no qual foram definidos os princípios e orientações para o futuro (HENRIQUES et al., 2007).

Em 1977, Tbilisi (Geórgia) sediou a Conferência Intergovernamental sobre EA, que teve como fruto as resoluções, definições, objetivos, princípios e as estratégias que são adotadas mundialmente para a EA (HENRIQUES et al., 2007).

Em 1988 foi promulgada a Constituição brasileira que incumbiu ao poder público a introdução da EA em todos níveis de ensino e a conscientização pública para a preservação do meio ambiente para a atual e futuras gerações (BRASIL, 1988). Quatro anos depois da promulgação da Constituição, o Rio de Janeiro sediou a Conferência Internacional Rio/92, com a participação de 170 países que reconheceram a educação como sendo o centro das transformações na construção de um mundo socialmente justo e ecologicamente equilibrado.

A promulgação da Constituição, a realização dessa conferência, bem como a pressão internacional levou o então presidente da república Fernando Henrique Cardoso, em 1999 a sancionar a Lei n. ${ }^{\circ} 9.795$ que como descreve Furtado (2009 apud ADAMS, 2012) assegura à temática ambiental um caráter transversal, indispensável e indissociável da política educacional brasileira.

De acordo com Adams (2012), para essa transversalidade é importante que os professores de todas as áreas conheçam não só essa lei, mas também os demais documentos que a legitimam, pois, caso contrário, a escola não poderá atuar de forma coerente com ela. Ainda de acordo com esse autor, sem esses conhecimentos a escola pode criar uma disciplina 
específica de EA, o que estaria em desacordo com os princípios dessa lei que é a transversalidade da EA. Nessa lei a EA foi conceituada no Art. $1 .^{\circ}$ como:

processos por meio dos quais o indivíduo e a coletividade constroem valores sociais, conhecimentos, habilidades, atitudes e competências voltadas para a conservação do meio ambiente, bem de uso comum do povo, essencial à sadia qualidade de vida e sua sustentabilidade (BRASIL, 1999).

A construção de valores sociais, conhecimentos, habilidades, atitudes e competências voltadas para a conservação do meio ambiente impõe uma mudança no modo de pensar e agir, tanto individual como coletivamente e a escola não pode ficar fora dessa mudança, uma vez que ela é um espaço que, como descrevem Santos e Santos (2016), pode criar condições que levem os alunos a terem concepções e posturas cidadãs em relação ao meio ambiente.

É necessário que o aluno compreenda suas responsabilidades e perceba que é um integrante do meio ambiente, ou seja, que ele faz parte de um todo e deve se interessar na solução de problemas ambientais. Mas, para criar condições que leve o aluno a uma postura ambiental responsável, é imprescindível o papel do professor (VALDUGA; DAL-FARRA, 2011).

Segundo Almeida (2013, p.127):

Grande parte dos cursos de licenciatura do Brasil entrega anualmente à sociedade, profissionais da educação que se encontram despreparados para atender às atuais necessidades sociais de uma formação cidadã menos excludente, menos desigual, mais participativa e democrática. Essa problemática se estende às formações continuadas e à capacitação dos profissionais da educação para o trabalho com a EA.

É preciso entender que a escola é o locus ideal para que os professores tenham acesso às discussões com seus pares sobre EA. Assim, cabe a equipe gestora identificar as deficiências dos seus docentes para o planejamento dessas discussões.

\section{METODOLOGIA}

Participaram dessa experiência 35 professores de todas as áreas do Ensino Fundamental e Médio em uma Escola estadual localizada na cidade de São Paulo. Inicialmente foram apresentados e discutidos os conceitos de EA propostos por Loureiro (2004), Sato et al. (2005), Sorrentino et al. (2005), Quintas (2008), Layrargues (2002), Mousinho (2003) e Trein (2008) que estão disponíveis no portal do ministério do meio ambiente. $\mathrm{O}$ quadro 1 apresenta esses conceitos:

\begin{tabular}{|l|l|}
\hline Conceito & Autor \\
\hline Entendem-se por educação ambiental os processos & Lei 9795/99 \\
por meio dos quais o indivíduo e a coletividade & \\
constroem valores sociais, conhecimentos, & \\
\hline
\end{tabular}


Ensino, Saúde e Ambiente - V12 (2), pp. 140-155, Ago. 2019

habilidades, atitudes e competências voltadas para a conservação do meio ambiente, bem de uso comum do povo, essencial à sadia qualidade de vida e sua sustentabilidade.

A Educação Ambiental é uma dimensão da educação, é atividade intencional da prática social, que deve imprimir ao desenvolvimento individual um caráter social em sua relação com a natureza e com os outros seres humanos, visando potencializar essa atividade humana com a finalidade de torná-la plena de prática social e de ética ambiental.

A educação ambiental é a ação educativa permanente pela qual a comunidade educativa tem a tomada de consciência de sua realidade global, do tipo de relações que os homens estabelecem entre si e com a natureza, dos problemas derivados de ditas relações e suas causas profundas. Ela desenvolve, mediante uma prática que vincula o educando com a comunidade, valores e atitudes que promovem um comportamento dirigido à transformação superadora dessa realidade, tanto em seus aspectos naturais como sociais, desenvolvendo no educando as habilidades e atitudes necessárias para dita transformação.

A educação ambiental é um processo de reconhecimento de valores e clarificações de conceitos, objetivando o desenvolvimento das habilidades e modificando as atitudes em relação ao meio, para entender e apreciar as inter-relações entre os seres humanos, suas culturas e seus meios biofísicos. A educação ambiental também está relacionada com a prática das tomadas de decisões e a ética que conduzem para a melhora da qualidade de vida.

Diretrizes Curriculares Nacionais para a Educação Ambiental. Art. $2^{\circ}$

Conferência Sub-regional de Educação Ambiental para a Educação Secundária - Chosica/Peru (1976)

Conferência Intergovernamental de Tbilisi (1977) 
Ensino, Saúde e Ambiente - V12 (2), pp. 140-155, Ago. 2019

\begin{tabular}{|c|c|}
\hline $\begin{array}{l}\text { A Educação Ambiental deve proporcionar as } \\
\text { condições para o desenvolvimento das capacidades } \\
\text { necessárias; para que grupos sociais, em diferentes } \\
\text { contextos socioambientais do país, intervenham, de } \\
\text { modo qualificado tanto na gestão do uso dos } \\
\text { recursos ambientais quanto na concepção e } \\
\text { aplicação de decisões que afetam a qualidade do } \\
\text { ambiente, seja físico-natural ou construído, ou seja, } \\
\text { educação ambiental como instrumento de } \\
\text { participação e controle social na gestão ambiental } \\
\text { pública. }\end{array}$ & Quintas (2008) \\
\hline $\begin{array}{l}\text { A Educação Ambiental nasce como um processo } \\
\text { educativo que conduz a um saber ambiental } \\
\text { materializado nos valores éticos e nas regras } \\
\text { políticas de convívio social e de mercado, que } \\
\text { implica a questão distributiva entre benefícios e } \\
\text { prejuízos da apropriação e do uso da natureza. Ela } \\
\text { deve, portanto, ser direcionada para a cidadania } \\
\text { ativa considerando seu sentido de pertencimento e } \\
\text { corresponsabilidade que, por meio da ação coletiva } \\
\text { e organizada, busca a compreensão e a superação } \\
\text { das causas estruturais e conjunturais dos problemas } \\
\text { ambientais. }\end{array}$ & Sorrentino et al. (2005) \\
\hline $\begin{array}{l}\text { A Educação Ambiental, apoiada em uma teoria } \\
\text { crítica que exponha com vigor as contradições que } \\
\text { estão na raiz do modo de produção capitalista, deve } \\
\text { incentivar a participação social na forma de uma } \\
\text { ação política. Como tal, ela deve ser aberta ao } \\
\text { diálogo e ao embate, visando à explicitação das } \\
\text { contradições teórico-práticas subjacentes a projetos } \\
\text { societários que estão permanentemente em disputa. }\end{array}$ & Trein (2008) \\
\hline $\begin{array}{l}\text { A EA deve se configurar como uma luta política, } \\
\text { compreendida em seu nível mais poderoso de } \\
\text { transformação: aquela que se revela em uma disputa }\end{array}$ & \\
\hline
\end{tabular}


Ensino, Saúde e Ambiente - V12 (2), pp. 140-155, Ago. 2019

\begin{tabular}{|c|c|}
\hline $\begin{array}{l}\text { de posições e proposições sobre o destino das } \\
\text { sociedades, dos territórios } \mathrm{e} \text { das } \\
\text { desterritorializações; que acredita que mais do que } \\
\text { conhecimento técnico-científico, o saber popular } \\
\text { igualmente consegue proporcionar caminhos de } \\
\text { participação para a sustentabilidade através da } \\
\text { transição democrática. }\end{array}$ & Sato et al. (2005) \\
\hline $\begin{array}{l}\text { Um processo educativo eminentemente político, } \\
\text { que visa ao desenvolvimento nos educandos de uma } \\
\text { consciência crítica acerca das instituições, atores e } \\
\text { fatores sociais geradores de riscos e respectivos } \\
\text { conflitos socioambientais. Busca uma estratégia } \\
\text { pedagógica do enfrentamento de tais conflitos a } \\
\text { partir de meios coletivos de exercício da cidadania, } \\
\text { pautados na criação de demandas por políticas } \\
\text { públicas participativas conforme requer a gestão } \\
\text { ambiental democrática. }\end{array}$ & Layrargues (2002) \\
\hline $\begin{array}{l}\text { Educação ambiental é uma perspectiva que se } \\
\text { inscreve e se dinamiza na própria educação, } \\
\text { formada nas relações estabelecidas entre as } \\
\text { múltiplas tendências pedagógicas e do } \\
\text { ambientalismo, que têm no "ambiente" e na } \\
\text { "natureza" categorias centrais e identitárias. Neste } \\
\text { posicionamento, a adjetivação "ambiental" se } \\
\text { justifica tão somente à medida que serve para } \\
\text { destacar dimensões "esquecidas" historicamente } \\
\text { pelo fazer educativo, no que se refere ao } \\
\text { entendimento da vida e da natureza, e para revelar } \\
\text { ou denunciar as dicotomias da modernidade } \\
\text { capitalista e do paradigma analítico-linear, não- } \\
\text { dialético, que separa: atividade econômica, ou } \\
\text { outra, da totalidade social; sociedade e natureza; } \\
\text { mente e corpo; matéria e espírito, razão e emoção } \\
\text { etc. }\end{array}$ & Loureiro (2004) \\
\hline
\end{tabular}


Ensino, Saúde e Ambiente - V12 (2), pp. 140-155, Ago. 2019

\begin{tabular}{|c|c|}
\hline $\begin{array}{l}\text { Processo em que se busca despertar a preocupação } \\
\text { individual e coletiva para a questão ambiental, } \\
\text { garantindo o acesso à informação em linguagem } \\
\text { adequada, contribuindo para o desenvolvimento de } \\
\text { uma consciência crítica e estimulando o } \\
\text { enfrentamento das questões ambientais e sociais. } \\
\text { Desenvolve-se num contexto de complexidade, } \\
\text { procurando trabalhar não apenas a mudança } \\
\text { cultural, mas também a transformação social, } \\
\text { assumindo a crise ambiental como uma questão } \\
\text { ética e política. }\end{array}$ & Mousinho (2003) \\
\hline
\end{tabular}

Quadro 1 - Conceitos de EA discutidos com os professores.

Fonte: http://www.mma.gov.br/educacao-ambiental/politica-de-educacao-ambiental.

Esses conceitos foram apresentados e discutidos durante as Aulas de Trabalho Pedagógico Coletivo (ATPCs). Para a discussão desses conceitos, os docentes foram divididos em grupo. Após essa análise e discussão, na reunião de ATPC seguinte, cada grupo recebeu o texto da autora Isabel Cristina Moura de Carvalho (2001) e a tarefa era que o interpretasse utilizando o diagrama V de Gowin.

A pouca utilização do diagrama $\mathrm{V}$, também conhecido como $\mathrm{V}$ heurístico, $\mathrm{V}$ epistemológico ou V de Gowin como instrumento de interpretação de um texto, deve-se ao fato de os docentes não o conhecerem, mas esse diagrama é um recurso pedagógico que pode ser utilizado com os alunos como um instrumento facilitador de aprendizagem significativa. Como descrevem Leboeuf e Batista (2013), o V de Gowin é uma maneira estruturada e visual de relacionar os aspectos metodológicos de uma atividade com seus aspectos conceituais e teóricos subjacentes.

A figura 1 mostra as etapas de construção de V de Gowin. 
Ensino, Saúde e Ambiente - V12 (2), pp. 140-155, Ago. 2019

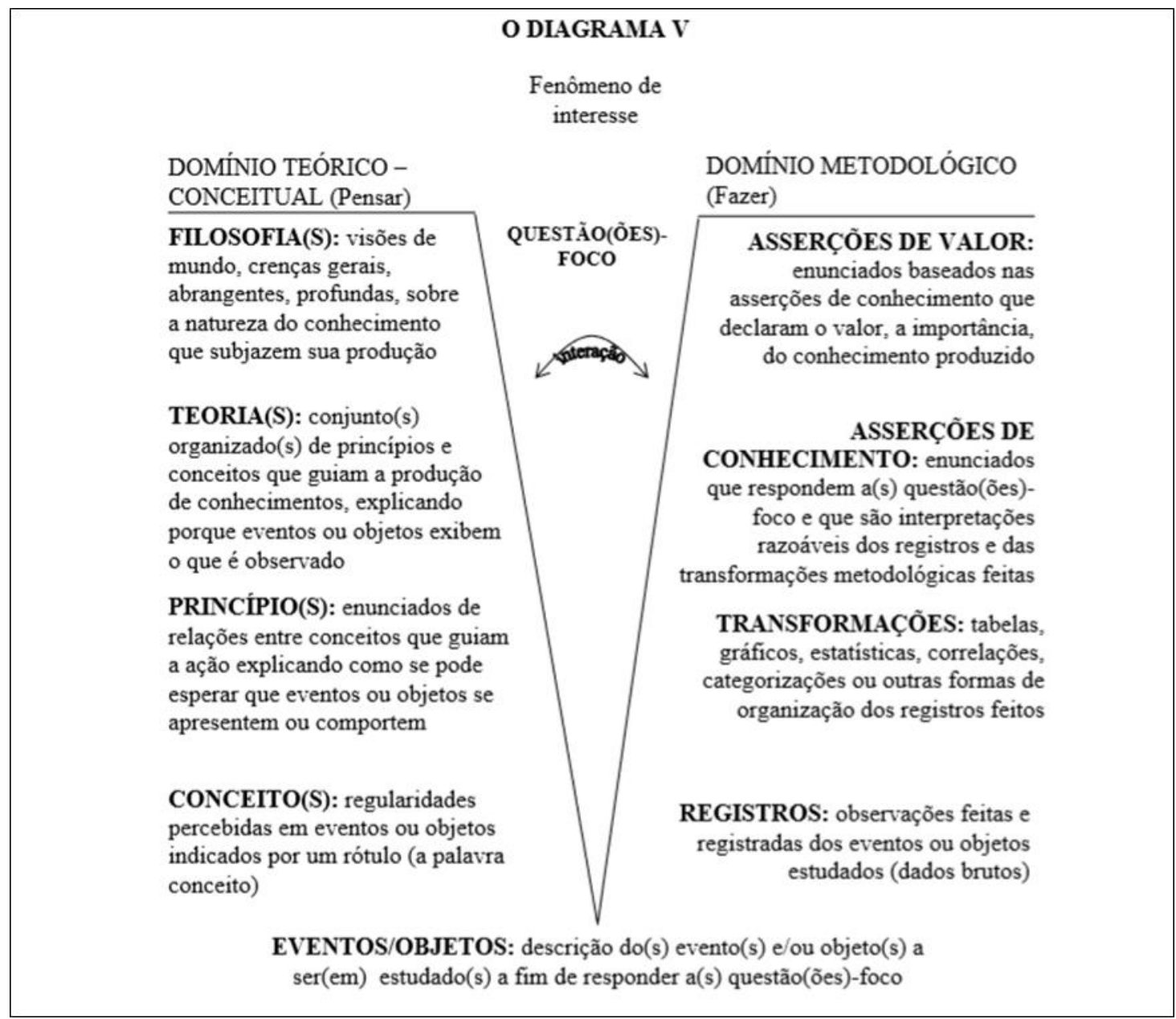

Figura 1- "V" de Gowin.

Fonte: Moreira (2012, p.3)

Ferracioli (2005) ressalta que a sua construção gera um processo sucessivo de questionamento em cada etapa a ser construída e que pode ser um importante instrumento para direcionar e auxiliar na realização dos objetivos a serem alcançados.

Ao término da construção, os docentes elegeram um representante de cada grupo para apresentar sua interpretação do texto.

\section{RESULTADOS E DISCUSSÃO}

Inicialmente os professores foram questionados se poderiam utilizar as reuniões de ATPCs para discutir conceitos de EA, uma vez que como professora tínhamos percebido que ela estava sendo desenvolvida na escola de maneira fragmentada e que uma forma de romper com essa fragmentação seria que todos conhecessem os vários conceitos de EA. Todos aceitaram e deu-se início à apresentação e discussão dos conceitos citados anteriormente. Após a leitura e estudo desses conceitos, cada grupo comentou que todos são bem parecidos e discutiram como entenderam a EA:

De forma bem resumida entendemos como Educação Ambiental a utilização dos recursos naturais

com responsabilidade social priorizando a sustentabilidade. A EA trabalha ética e melhora a 
Ensino, Saúde e Ambiente - V12 (2), pp. 140-155, Ago. 2019

qualidade de vida das pessoas. Desenvolve competências, habilidades e atitudes em relação ao meio ambiente e a sociedade (Grupo 1).

A sociedade deve intervir na gestão dos recursos ambientais e a escola é responsável em desenvolver ações para sensibilizar e preparar sua comunidade para essa gestão (Grupo 2).

As definições de Quintas e Sorrentino são complementares e elas falam da importância da ação em cima dos valores éticos e dos valores de cidadania. Sorrentino também fala da questão do mercado que para ele implica na questão de equilíbrio entre benefícios e prejuízos da apropriação e do uso da natureza. Para nosso grupo o mercado não tem nenhuma preocupação e não tem nenhum valor ético (Grupo 3).

EA faz parte de um movimento pós-moderno que leva em consideração as demandas coletivas em relação a natureza. Faz parte de um desenvolvimento de políticas públicas e legislação educacional, instrumentalizado com a importância dos valores éticos com o intuito de promover a cidadania (Grupo 4).

A EA deve prevalecer sobre o modo de produção capitalista, o que de certa forma para alguns é só uma utopia. Na verdade é. Para esse autor é preciso perceber que é na raiz do sistema capitalista de produção que é gerada a dificuldade de se produzir na prática uma EA (Grupo 5).

Como pode ser observado nessas falas, os grupos 1, 2 e 4 descreveram como tinham entendido a EA, enquanto os outros fizeram uma interpretação dos conceitos dos autores. Esses grupos remetem a uma visão da EA comportamental (Grupos 1 e 2) e popular (Grupo 4). Segundo Carvalho (2001a), a ideologia pedagógica e as práticas da EA estão inseridas em dois grandes grupos: EA Comportamental e EA Popular. A primeira, como o próprio nome indica, se preocupa com a mudança de comportamento do homem frente ao meio ambiente. Neste caso, a escola passa a ser a propagadora de todo o conhecimento sobre o meio ambiente e isso inclui a mudança de comportamentos que são nocivos, para comportamentos que venham a preservar os recursos naturais.

Sobre a EA popular, esse autor a define como sendo de uma postura crítica com prática social intensa e com uma formação cidadã para a transformação da sociedade, a partir das relações dos seres humanos com o meio ambiente. Essa transformação pode ocorrer dentro de um "projeto de construção de um novo ethos social, baseado em valores libertários, democráticos e solidários” (CARVALHO, ICM 2001, p.47).

Ao final dessa discussão, todos os grupos concordaram que a EA deve ser inserida no PPP como uma ação contínua e permanente para uma sensibilização do aluno na defesa do meio ambiente, em uma linha mais crítica, uma vez que a escola pretende que a criticidade do modo de produção e consumo faça parte do contexto escolar, e para isso exige que os professores tenham uma linha mais reflexiva de ensino.

É importante enfatizar que durante o desenvolvimento dessa atividade a colaboração da vice-diretora foi importante, pois ela ressaltou a importância do trabalho para a escola, uma vez que a EA não consta no PPP, e que, a fim de a escola cumprir a Lei 9795/99, a EA deve estar inserida nesse documento. A vice-diretora também lembrou que no ano de 2018 vencia o quadriênio para a revisão do Plano de Gestão, e reforçou a importância da adição da temática no PPP, que é revisto anualmente. 
Ensino, Saúde e Ambiente - V12 (2), pp. 140-155, Ago. 2019

Essa discussão avançou para uma questão importante que é a fragmentação dos projetos que tratam a EA na escola. Os professores argumentaram que é preciso que esta seja incorporada de forma permanente, entretanto, eles se sentem inseguros em desenvolver atividades que envolvam questões ambientais. Quanto a essa questão Carvalho LM (2001) enfatiza que:

não existem fórmulas prontas e mágicas para o desenvolvimento de práticas educativas relacionadas à temática ambiental. Será a partir de reflexões cuidadosas e escolhas conscientes, dentre diferentes possibilidades de avaliações sistemáticas e inovações criativas, que novas perspectivas poderão ser traçadas (CARVALHO, LM 2001, p. 58).

Para traçar essas novas perspectivas descritas acima por Carvalho LM (2001), Azanha (2004) propõe que é preciso que o professor tenha um espaço para discutir e refletir junto com seus pares sobre a EA. Entretanto, o que se percebe no contexto escolar é que há muitos problemas a serem resolvidos como por exemplo, a carga horária exacerbada que não permite ao professor tempo e espaço para realizar uma discussão sobre a EA, embora alguns entendam que o conhecimento dos princípios fundamentais que a sustenta deve ser uma discussão permanente dentro do ambiente escolar.

Sobre isso, Sato (2001, p.24) comenta: "não temos dúvidas de que a EA exige um debate sobre suas bases de sustentação, com aberturas epistemológicas que confiram seu alto poder de diversidade e interfaces que a sua própria natureza requer".

Muitas vezes, esse debate não acontece na escola porque, além da carga horária do professor como descrito anteriormente, os seus conhecimentos sobre EA são insuficientes, pois como descrevem Mello, Montes e Lima (2009) não foram preparados na sua formação inicial, embora a Lei 9795/99 preveja a obrigatoriedade da inserção dessa temática nos cursos de formação inicial de professores.

Para Boton et al. (2010, p.3) "é necessário que, além do conhecimento da disciplina que irá ensinar, o docente domine minimamente o arcabouço teórico e didático pertinente à Educação Ambiental".

Entretanto, o que se tem observado na literatura é que esse domínio mínimo não está acontecendo na formação inicial dos professores. Várias pesquisas apontam a deficiência da abordagem da EA em cursos de formação inicial de professores. Entre essas pesquisas está a desenvolvida por Costa (2009). Segundo esse autor, nos cursos da universidade onde ele desenvolveu sua pesquisa, a EA tem uma abordagem precária no contexto curricular, estando fragmentada, a cargo de iniciativas pessoais de alguns professores.

Após constatar a visão dos professores quanto ao tipo de EA, na reunião de ATPC seguinte foi apresentado aos professores o texto de Carvalho ICM (2001) que discute os dois 
Ensino, Saúde e Ambiente - V12 (2), pp. 140-155, Ago. 2019

tipos de EA: a comportamental e a popular. Como forma de interpretação desse texto, foi solicitado que utilizassem o $\mathrm{V}$ de Gowin. A escolha por esse instrumento deve-se ao fato de os professores nunca terem ouvido falar dele e desse diagrama ser um recurso pedagógico que pode ser utilizado depois com seus alunos como facilitador de uma aprendizagem significativa, uma vez que, como descrevem Leboeuf e Batista (2013), o V de Gowin é uma maneira estruturada e visual de relacionar aspectos metodológicos de uma atividade com seus aspectos conceituais e teóricos subjacentes.

As figuras 2 e 3 mostram o $\mathrm{V}$ de Gowin com a interpretação desse texto pelos Grupos 1 e 2, respectivamente.

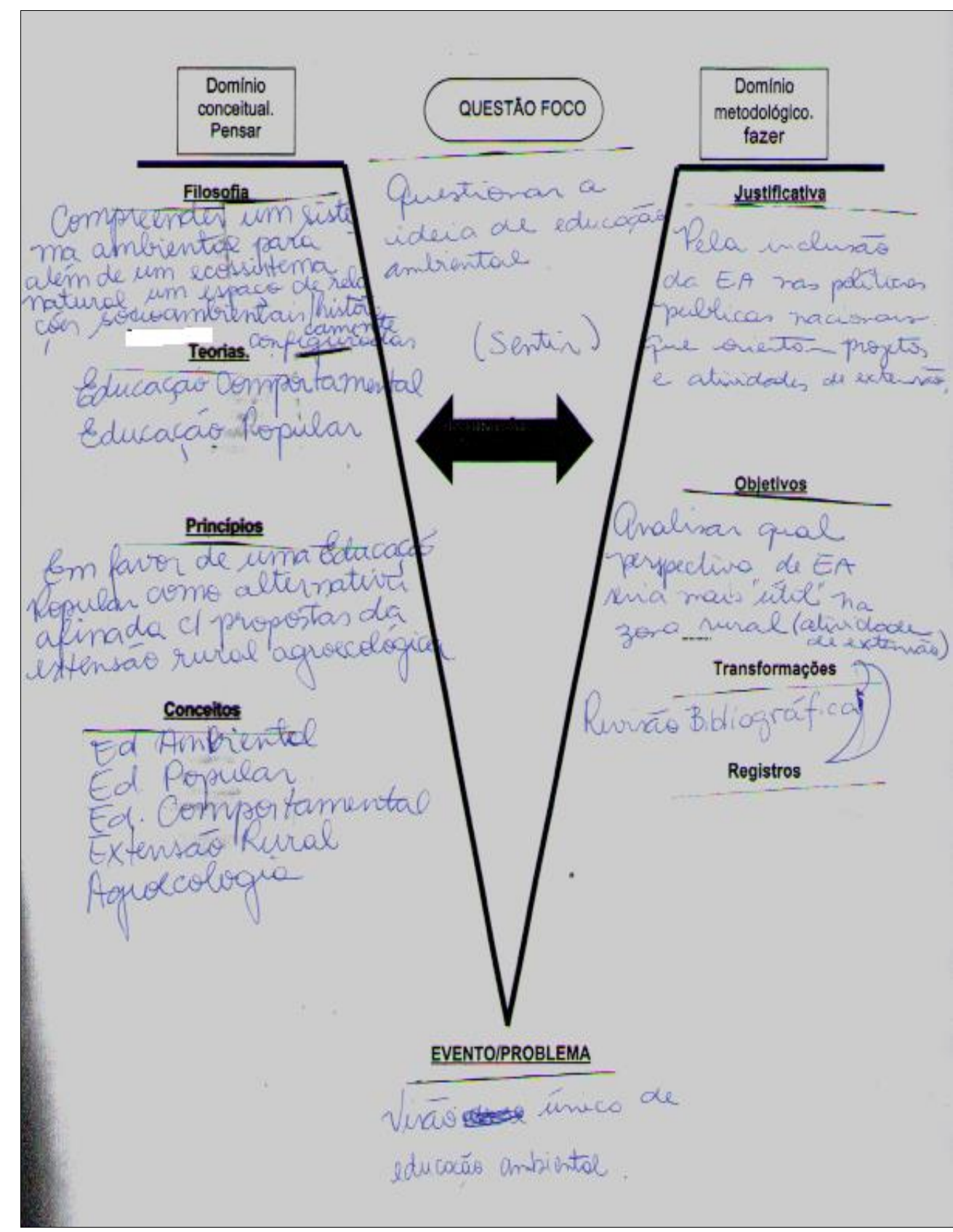

Figura 2- "V" de Gowin construído pelo Grupo 1

Fonte: Autoras 
Ensino, Saúde e Ambiente - V12 (2), pp. 140-155, Ago. 2019

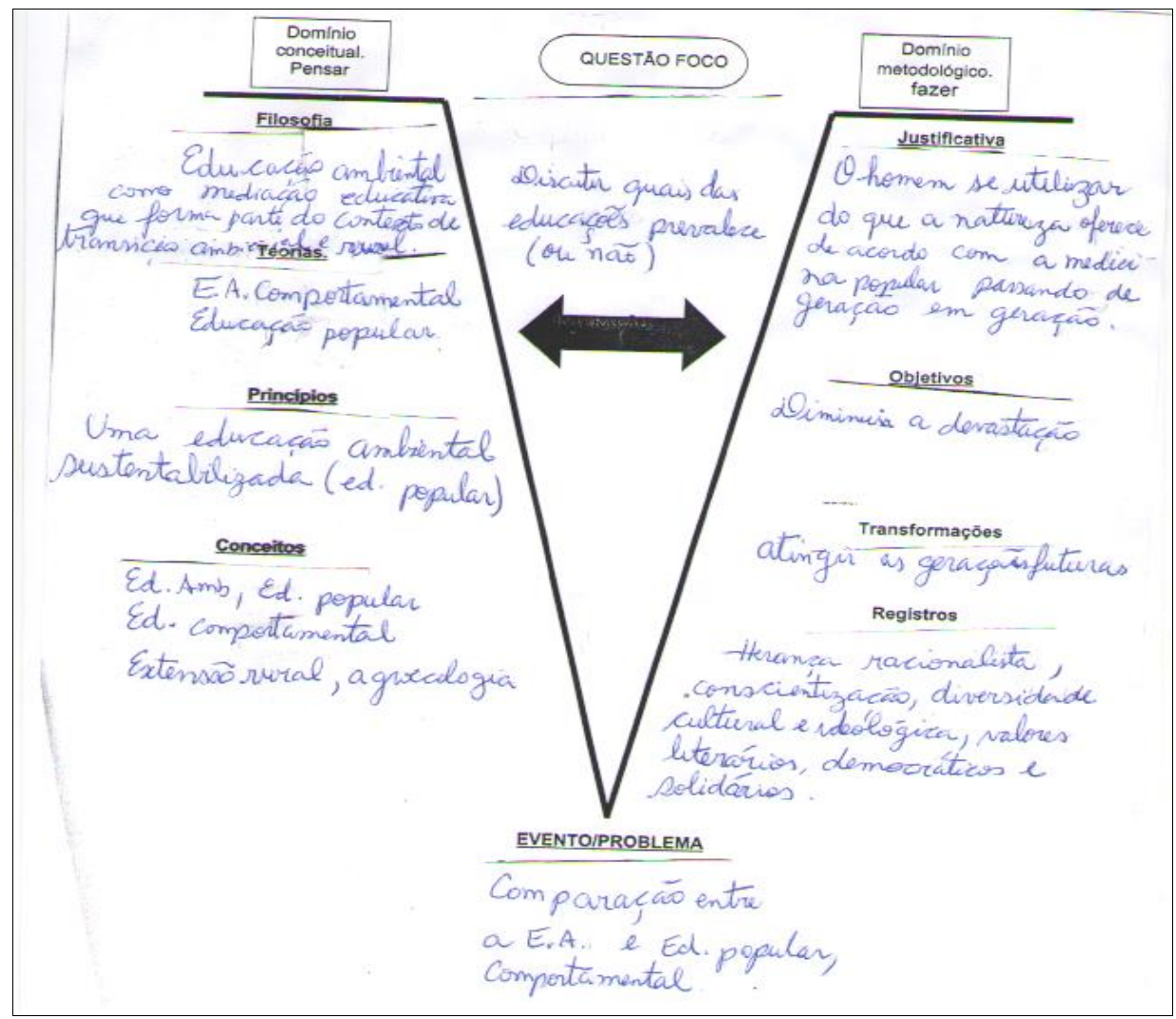

Figura 3- "V" de Gowin construído pelo Grupo 2.

Fonte: Autoras

Ao comparar esses 2 Vs de Gowin, os docentes foram questionados se as versões estavam iguais. Todos foram unânimes em responder que as duas versões eram totalmente diferentes. Uma docente do Grupo 1 comentou:

Criar os conceitos dentro do texto nós não podemos fazer, a menos que se peça um trabalho de interpretação. Temos que nos concentrarmos no que o autor está explicando, qual a proposta dele.

A coordenadora interrompeu e explicou para todos:

O que estamos fazendo nessa reunião é um estudo dirigido que para mim não deixa de ser aquilo que a gente chama de dupla contextualização, ou seja, apresenta-se um conceito e o interpreta. Nesse momento, a gente não pode colocar aquilo que pensamos, pois, a tarefa era interpretar o que o autor está dizendo. Nós enquanto educadores, as vezes temos dificuldades em ler e obter informações a partir daquilo que a gente está lendo porque queremos sempre associar com aquilo que a gente já sabe, que a gente já conhece.

Outra docente complementou:

Mas que é a nossa leitura é carregada da nossa visão de mundo.

Ao final todos concordaram que o Grupo 2 fez uma interpretação pessoal do texto com a sua opinião, deixando de retirar as ideias que seriam naturais do pensamento da autora.

A coordenadora ao pontuar as dificuldades que os docentes tiveram em interpretar o artigo, ponderou a importância desse tipo de atividade. Para ela esse tipo de atividade deveria ser frequente nessas reuniões da escola, para auxiliar o professor no seu trabalho em sala de aula com a finalidade de melhorar a qualidade do ensino. 
Ensino, Saúde e Ambiente - V12 (2), pp. 140-155, Ago. 2019

Para Leboeuf e Batista (2013), as dificuldades na construção do V de Gowin provenientes da sua complexidade e da não familiaridade dos professores devem ser encaradas, não como obstáculos, mas como desafios inerentes à construção de conhecimentos.

Sobre a importância da participação de atividades em grupos por professores, Lopes et al. (2011, p. 528), comentam que "a participação em grupos de estudos coletivos contribui para o aumento do conhecimento teórico e metodológico e melhora o desenvolvimento da prática reflexiva do professor". Para os autores é importante que esses espaços de debates coletivos sejam valorizados, pois os professores de educação básica possuem experiências e conhecimentos para trocar ideias e saberes.

\section{CONSIDERAÇÕES FINAIS}

Ao entenderem os conceitos de EA, os docentes perceberam que esta é parte integrante do contexto escolar e deve ser posta em prática como tema transversal e interdisciplinar e ser incorporada ao PPP da escola. Com essa discussão, os docentes deram um passo inicial para modificar o cenário da EA na escola.

$\mathrm{O}$ V de Gowin mostrou ser um importante instrumento para esmiuçar os conceitos de EA e auxiliar os professores na interpretação de ideias contidas em um artigo científico. Essa atividade contribui para a sua prática educativa, à medida que possibilita uma reflexão em seu modo de pensar e contextualizar um texto. Sua utilização pode impulsionar as concepções de EA e assim proporcionar a reflexão, intensificando a sistematização de registros sobre um tema tão importante nos dias atuais.

\section{REFERÊNCIAS}

ADAMS, B.G. A importância da lei 9.795/99 e das diretrizes curriculares nacionais da educação ambiental para docentes. Monografias Ambientais. v.10, n. 10, p. 2148 - 2157, 2012.

ALMEIDA, J.P. Formação docente para a promoção da Educação Ambiental: O caso de uma escola estadual em Maceió (Al). Revista Brasileira de Educação Ambiental, v. 8, n.1, p.114-129, 2013.

AZANHA, J.M.P. Uma reflexão sobre a formação do professor da escola básica. Educação e Pesquisa, v.30, n.2, p. 369-378, 2004.

BOTON, J.M.; COSTA, R.G.A.; KURZMANN, S.M.; TERRAZZAN, E.A. O meio ambiente como conformação curricular na formação docente. Ensaio Pesquisa em Educação em Ciências. v.12, n.3, p. 41-50. 2010.

BRASIL. Lei n ${ }^{\circ}$ 9.795, de 27 de abril de 1999 (Política Nacional de Educação Ambiental). Diário Oficial da União. Brasília, DF, 27 abril de 1999.

. Constituição Federal de 1988. Promulgada em 5 de outubro de 1988. Disponível em http://www.planalto.gov.br/ccivil_03/constituicao/constituição.htm. Acesso em: 31/ jan./2018 
CARVALHO, I.C.M. Qual educação ambiental? Elementos para um debate sobre educação ambiental e extensão rural. Agroecologia e Desenvolvimento Rural Sustentável, v.2, n.2, p.43-51, 2001.

CARVALHO, L.M. A Educação Ambiental e a formação de professores. In: Panorama da Educação Ambiental no Ensino Fundamental. Brasília: MEC; SEF, 2001. Disponível em: http://portal.mec.gov.br/secad/arquivos/pdf/educacaoambiental/panorama.pdf. Acesso em: 02 fev. 2018

COELHO-MIYAZAWA, G.C. M.; CURI, E.; FRENEDOZO, R.C. A educação ambiental na formação inicial de professores: um panorama das teses e dissertações brasileiras (20102016). Ensino, Saúde e Ambiente, v.10, n.2, p. 39-56, 2017.

COSTA, R.G.A. Um olhar crítico sobre a educação ambiental na formação de professores em uma instituição de ensino superior gaúcha. Revista Eletrônica do Mestrado Educação Ambiental v. 22, p. 177-187, 2009.

FERRACIOLI, L. O 'V' Epistemológico como Instrumento Metodológico para o Processo de Investigação. Revista Didática Sistêmica v. 1, p. 106 - 195, 2005. Disponível em: http://www.mettodo.com.br/pdf/V_de_Gowin.pdf. Acesso em: 17 jan. 2018.

HENRIQUES, R.; TRAJBER, R.; MELLO, S.; LIPAI, E.M.; CHAMUSCA, A. Educação Ambiental: aprendizes de sustentabilidade. Cadernos Secad: Ministério da Educação Continuada, Alfabetização e Diversidade, 2007. Disponível em: http://portal.mec.gov.br/dmdocuments/publicacao2.pdf. Acesso: 20 ago. 2018.

LEBOEUF, H.A.; BATISTA, I.L. O uso do "V" de Gowin na formação docente em ciências para os anos iniciais do ensino fundamental. Investigações em Ensino de Ciências, v.18, n.3, p. 697-721, 2013.

LOPES, I. S. et al. Estudos coletivos de educação ambiental como instrumento reflexivo na formação continuada de professores de ciências em espaços educativos formais e não-formais. Revista Electrónica de Enseñanza de las Ciencias, v.10, n.3, p. 516-530, 2011.

LUCA, A.Q.; LAGAZZI, S.M.; SORRENTINO, M. Educação Ambiental e análise de discurso: Uma proposta de pesquisa. Disponível em: https://www.researchgate.net/publication/277201251/download. Acesso em 02 jun. 2018.

MELLO, A.S.; MONTES, S.R.; LIMA, L. Educação ambiental em curso de formação continuada para docentes do ensino básico-Uberlândia (MG). Em extensão, v. 8, n. 1, p. 48 $59,2009$.

MOREIRA, M.A. Diagramas V e aprendizagem significativa. 2012. Disponível em: https://www.if.ufrgs.br/ moreira/DIAGRAMASpor.pdf. Acesso em: 29 jul. 2018.

OLIVEIRA M.A.N. (Re)Pensando a formação de professores em Educação Ambiental.

Revista Monografias Ambientais, Edição Especial Curso de Especialização em Educação Ambiental, v.14, p. 08-16, 2015.

SANTOS, A.G.; SANTOS, C.A.P. A inserção da educação ambiental no currículo escolar. Revista Monografias Ambientais - REMOA v. 15, n.1, p.369-380, 2016.

SATO, M. Apaixonadamente Pesquisadora em Educação Ambiental. EDUCAÇÃO: Teoria e Prática, v.9, n. 16, p. 24-35, 2001.

VALDUGA, M.; DAL-FARRA, R.A. Formação docente continuada e Educação Ambiental: construindo práticas compartilhadas. In: VIII Encontro Nacional de Pesquisa em Educação em Ciências, 8, 2011, Campinas, SP. Anais.......Campinas, SP, 2011. Disponível em: http://www.nutes.ufrj.br/abrapec/viiienpec/resumos/R0868-3.pdf. Acesso: 30 jun. 2018. 


\section{SOBRE AS AUTORAS}

AUTORA 1. Atualmente é doutoranda na Universidade Cruzeiro do Sul em Ensino de Ciências e Matemática. Frequentou o Mestrado em Ensino de Ciências (área de concentração Ensino de Ciências e Matemática), na Universidade Cruzeiro do Sul. No presente trabalho atuou como pesquisadora.

AUTORA 2. Mestrado e Doutorado em Química Orgânica pela Universidade de São Paulo, atualmente é professora titular III da Universidade Cruzeiro do Sul, professora pesquisadora do programa de Mestrado e Doutorado em Ensino de Ciências e Ensino de Ciências e Matemática da Universidade Cruzeiro do Sul. No presente trabalho atuou como orientadora. 